\title{
The Influence of the Carbon Dioxide-steam Alternate Ratio and the Permeability Difference Affect Oil Recovery of Steam Composite Flooding
}

\author{
Tao-Ping Chen*1 ${ }^{*}$ Shuang Liuªnd Rui-Jie Cui ${ }^{3}$ \\ The Key Laboratory of Enhancing Oil and Gas Recovery Efficiency of Educational Ministry, \\ Northeast Petroleum University, Daqing, Heilongjiang, China, 163318

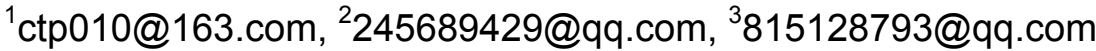

\begin{abstract}
Keywords: Heavy Oil, Carbon Dioxide-Steam Composite Flooding, Permeability Difference, Enhanced Oil Recovery.
\end{abstract}

\begin{abstract}
By means of 4 groups $10 \mathrm{~m}$ single-filled sand pipe models with the same permeability and 5 groups of double-filling sand pipe models with $10 \mathrm{~m}$ average 5 permeability difference of $1.00,1.85,2.80,3.65$ and 4.29 , The optimal alternation ratio of carbon dioxide-steam flooding after steam flooding and the effectiveness of composite flooding to enhance oil recovery in a range of permeability difference are studied. The experimental temperature is $200{ }^{\circ} \mathrm{C}, 4$ groups of single-tube model oil displacement experiments are carried out. The steam is driven to water cut of more than $98 \%, 0.5 \mathrm{ml}(0.0078 \mathrm{PV})$ high-temperature foaming agent is injected. Then carbon dioxide-steam is injected alternately by $1: 1,1: 2,1: 3,1: 4$. The result shows that the optimal ratio of carbon dioxide-steam is $1: 1$. Base on carbon dioxide-steam optimal proportion of $1: 1$ alternately 5 permeability difference for 1 4.29 double tube model oil displacement experiments are finished. The result shows that the composite flooding increase recovery is $13.29 \% \sim 23.82 \%$ under the condition of heterogeneity, the effect is remarkable.
\end{abstract}

\section{Introduction}

Steam flooding technology is one of the main technologies in heavy oil exploitation. In field test and industrial application, due to the influence of steam channeling and gravity override in displacement, the steam sweep efficiency is reduced and the oil recovery is greatly reduced. water cut rises too fast, the cost of recovery rises, a large number of laboratory experiments and field tests have been done in this area[1]. In the literature [2], using theoretical analysis and laboratory experiments, the feasibility of nitrogen, carbon dioxide assisted auxiliary steam to exploit heavy oil efficiently was studied. In the literature [3], according to the characteristics of the oil reservoir in Q i 40 block, the paper provided the basis for the reasonable exploitation of the pilot area of steam drive test. In the literature [4], based on the experimental research of carbon dioxide surfactant assisted steam flooding, the best way to enhanced oil recovery is given. Recently, there are few studies on the injection-production parameters optimization of carbon dioxide-steam in steam complex flooding, therefore, in view of the carbon dioxide gas source is sufficient or produced gas contains large amounts of carbon dioxide, The optimal alternate ratio of carbon dioxide-steam and the effect of different permeability differences on the recovery were studied, which provided the basis for field testing and application.

\section{Research on Alternate Ratio of Carbon Dioxide-Steam}

Experimental Study on Oil Displacement in Single Tube Model. The single tube model steam flooding and carbon dioxide-steam flooding experiments are carried out to optimize the carbon dioxide-steam alternate ratio. 


\section{Major equipment and materials}

(1) the main equipment

HBCD-70 high temperature and high pressure core displacement device, HBS series high pressure constant speed constant pressure pump, high pressure steam generator, the piston container, carbon dioxide gas cylinders, back pressure valve, pressure sensor, the working range of $0 \sim 300^{\circ} \mathrm{C}$ calorstat.

(2) experimental materials

Core: $10 \mathrm{~m}$ sand filling tube, crude oil: Qi 40-23-33C simulated oil; viscosity is $2634 \mathrm{mPa} \cdot$ $\mathrm{s}\left(50^{\circ} \mathrm{C}\right)$; steam for flooding: water; saturated water: $6778 \mathrm{mg} / \mathrm{L}$ saline; carbon dioxide: carbon dioxide in gas cylinder; surfactant: YL3 high temperature foaming agent, concentration: $0.3 \%$.

\section{Experiment scheme and basic parameters}

(1) experiment scheme

After water cut reach $98 \%$ in the process of steam flooding, $0.5 \mathrm{ml}(0.0078 \mathrm{PV})$ surfactant (YL3 high-temperature foaming agent, concentration: $0.3 \%)$ is injected, then carbon dioxide-steam is injected alternately by $1: 1,1: 2,1: 3,1: 4,0.5 \mathrm{ml}(0.00848 \mathrm{PV})$ carbon dioxide slug is injected at each time, the total injected carbon dioxide slug sizes are $0.15 \mathrm{PV}$ and alternate periods are 19 times, finally, subsequent steam flooding to the water cut of more than $98 \%$ end the experiment.

(2) the basic parameters of single tube model

The experiments are carried out in four groups of $10 \mathrm{~m}$ single tube sand filling pipe models $1,2,3$ and 4 with basically the same permeability. the basic parameters and injection parameters of the model are shown in Tab. 1.

Tab. 1 Basic parameters of single tube model

\begin{tabular}{|l|l|l|l|l|}
\hline Number & $\begin{array}{l}\text { Diameter } \\
\mathrm{cm}\end{array}$ & $\begin{array}{l}\text { Porosity } \\
\%\end{array}$ & $\begin{array}{l}\text { Air permeability } \\
10^{-3} \mathrm{~m}^{2}\end{array}$ & $\begin{array}{l}\text { Oil saturation } \\
\%\end{array}$ \\
\hline 1 & 0.4750 & 36.08 & 2565 & 59.79 \\
\hline 2 & 0.4427 & 36.61 & 2616 & 62.40 \\
\hline 3 & 0.4427 & 37.32 & 2461 & 60.57 \\
\hline 4 & 0.4427 & 38.00 & 2494 & 59.32 \\
\hline
\end{tabular}

Experimental Results and Analysis. Enhanced oil recovery rate of carbon dioxide-steam flooding is recorded real-timely under different injection (PV number) after steam driving. Experimental results of flooding in different displacement ways are shown in Tab. 2

Tab. 2 Carbon dioxide-steam flooding experimental results in single tube model

\begin{tabular}{|c|c|c|c|c|}
\hline \multirow{2}{*}{ Number } & \multirow{2}{*}{ Alternate ratio } & \multicolumn{3}{|l|}{ Recovery（\%) } \\
\hline & & Steam flooding & Composite flooding & total \\
\hline 1 & $1: 1$ & 70.01 & 4.09 & 74.10 \\
\hline 2 & $1: 2$ & 60.68 & 4.47 & 65.15 \\
\hline 3 & $1: 3$ & 57.90 & 1.93 & 59.83 \\
\hline 4 & $1: 4$ & 58.88 & 2.59 & 61.47 \\
\hline
\end{tabular}

According to Tab. 2, the curves of carbon dioxide-steam flooding in different alternate ratios (1: 1, 1:2, 1:3,1:4) are shown in Fig. 1.

In order to facilitate the comparison and analysis, the change of steam flooding phase recovery degree with the PV number is averaged, on the basis of the average curve, drawing carbon dioxide-steam contrast curves with different alternate proportion as shown in Fig. 2.

Fig. 2 shows that in the 4 groups of single tube model flooding experiments, the ratio $1: 1$ of carbon dioxide-steam alternate recovery is the highest recovery rate. Therefore, the best alternate ratio of carbon dioxide-steam is $1: 1$. 
In the process of single tube model steam flooding, steam will distill the light components in the heavy oil. As light fractions are continuously extracted from the contacting heavy oil, the light oil zone like solvent is increasing and eventually forms miscible flooding of oil. In the heavy oil, the dissolved gas will escape from the heated heavy oil, the expansion of the dissolved gas continuously form elastic force drive, the heavy oil is produced by this drive. After the water cut of the steam flooding reaches $98 \%, 0.5 \mathrm{ml}(0.0078 \mathrm{PV})$ of the high temperature foaming agent is injected, then the carbon dioxide-steam is injected in a certain alternate ratio. At this stage, Carbon dioxide-surfactant forms foam and plug high permeable zone to make subsequent injection fluid flow into the low permeability of the higher oil content reservoir, expanding the sweep volume and enhancing displacement efficiency. However, the cross-sectional area and diameter of the sand filling pipe are small, and the model is homogeneity, in the previous steam flooding, a large amount of heavy oil has been produced, so single tube model recovery degree of composite flooding is smaller.

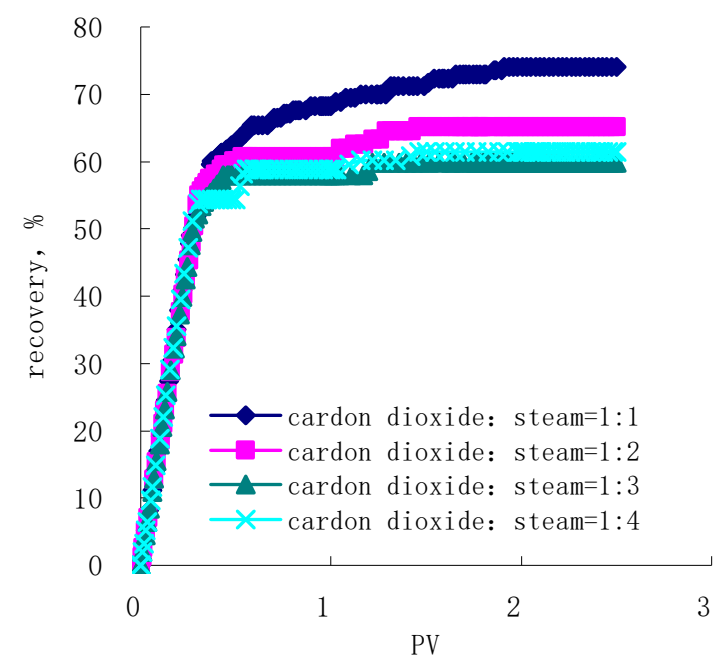

Fig. 1 Curve of carbon dioxide - steam flooding

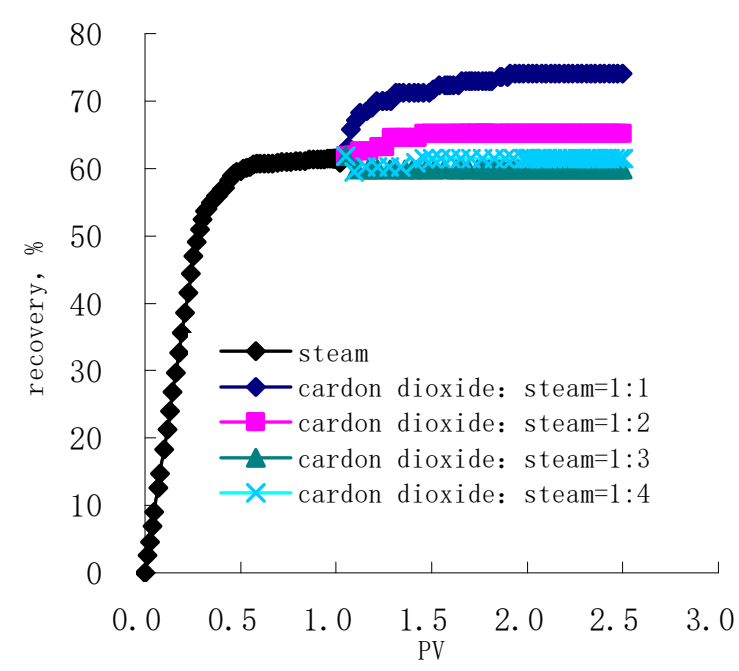

Fig. 2 Comparison curves of different alternating ratios

According to Tab. 2, the relation curves between the recovery ratio and alternate ratio in carbon dioxide-steam flooding. As shown in Fig. 3.

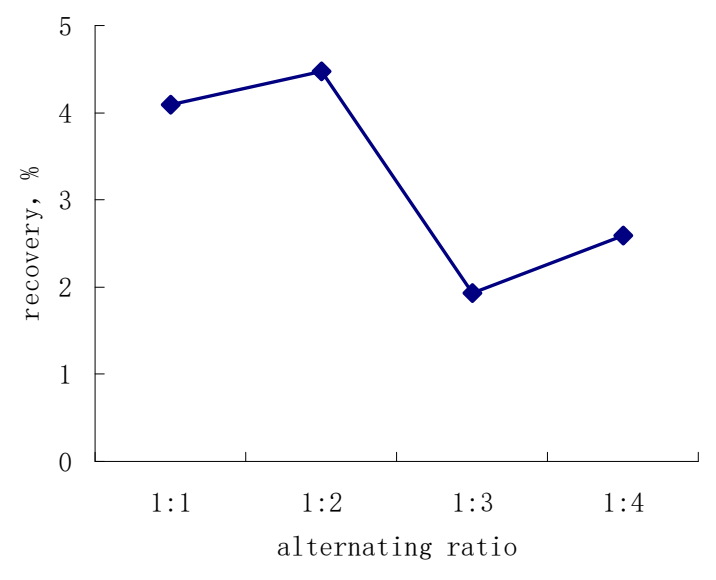

Fig. 3 Carton dioxide-steam alternate ratio and recovery curve

It can be seen from Fig. 3 that carbon dioxide-steam is injected alternately at the ratio of 1: 1, 1:2, $1: 3,1: 4$, the recovery ratio increase by $4.09 \%, 4.47 \%, 1.93 \%$ and $2.56 \%$ respectively, the alternate ratio of 1: 1 and 1:2 increase recovery greatly. The recovery ratio of composite flooding with 1: 1 is 
$0.38 \%$ lower than that of $1: 2$, and the recovery efficiency of steam flooding is $9.33 \%$ higher than that of 1: 2. Therefore, the total recovery ratio is $8.95 \%$ higher than that of 1: 2 . Based on the analysis of the oil recovery at each stage, after the steam flooding, the carton dioxide-steam is injected alternately at the ratio of 1: 1, the more remaining oil can be displaced from the No.1 model. Therefore, the optimal alternate ratio of carbon dioxide-steam is 1: 1 .

Analysis of the reasons are : (1) Carbon dioxide is soluble in crude oil, and its solubility is 3 9 times higher than that in water, so the volume of crude oil is expanded, the viscosity is reduced, the oil is enhanced, the oil relative permeability is increased, and the oil displacement efficiency is further improved[5]. (2) When carbon dioxide dissolves in water to form carbonic acid water, water viscosity increases, the mobility of water weakens, the crude oil is influenced by the role of carbon dioxide carbonation, the viscosity of crude oil decreases, mobility increases. Therefore, this way improve the mobility ratio of oil-water and enhance the oil displacement efficiency. (3) During the carbon dioxide flooding process, a large amount of carbon dioxide is dissolved in the crude oil. As the injection pressure rises, the amount of carbon dioxide dissolved in the crude oil increases. When carbon dioxide is no longer injected into the model, part of the carbon dioxide is separated from the crude oil and form dissolved gas flooding. (4) The injected carbon dioxide is in contact with the crude oil, and carbon dioxide can extract light hydrocarbon components from the crude oil (extraction, evaporation, vaporization) and make itself enrichment; The enrichment carbon dioxide contact crude oil again to extract crude oil further, contact again and further extract circularly, this phenomenon will be benefit for enhancing recovery ratio .

\section{Research on the Effects of Permeability Difference for Recovery}

Experimental Study on Oil Displacement in Double Tube Model. In these experiments, a 10 $\mathrm{m}$ double tube heterogeneous physical model is fabricated by using natural oil sands replace natural core to ensure that the experimental results are close to the actual situation. 5 groups of the $10 \mathrm{~m}$ double tube model experiments are finished. Basic parameters of double tube model are shown in Tab. 3 .

Tab. 3 Basic parameters of double tube model

\begin{tabular}{|c|c|c|c|c|}
\hline Group & Permeability difference & $\begin{array}{l}\text { Average oil saturation } \\
\%\end{array}$ & $\begin{array}{l}\text { Porosity } \\
\%\end{array}$ & $\begin{array}{l}\text { Air permeability } \\
10^{-3} \mu^{2}\end{array}$ \\
\hline \multirow{2}{*}{1} & \multirow{2}{*}{1.00} & \multirow{2}{*}{59.79} & 36.08 & 2565 \\
\hline & & & 36.10 & 2568 \\
\hline \multirow{2}{*}{2} & \multirow{2}{*}{1.85} & \multirow{2}{*}{66.29} & 35.01 & 1762 \\
\hline & & & 34.23 & 3264 \\
\hline \multirow{2}{*}{3} & \multirow{2}{*}{2.80} & \multirow{2}{*}{52.78} & 36.64 & 3809 \\
\hline & & & 36,93 & 1360 \\
\hline \multirow{2}{*}{4} & \multirow{2}{*}{3.65} & \multirow{2}{*}{56.08} & 38.54 & 3974 \\
\hline & & & 35.60 & 1090 \\
\hline \multirow{2}{*}{5} & \multirow{2}{*}{4.29} & \multirow{2}{*}{56.43} & 34.73 & 973 \\
\hline & & & 35.00 & 4176 \\
\hline
\end{tabular}

Experimental program: Firstly, 5 groups different permeability difference of the double tube model are drived to the water cut of $98 \%$ by steam flooding; Secondly, $0.5 \mathrm{ml}(0.0078 \mathrm{PV})$ of high temperature foaming agent (Yulon 3 high temperature foaming agent, concentration: $0.3 \%$ ) is injected, the experiments are carried out by injecting carbon dioxide-steam with a slug size in the alternate ratio of $1: 1$, the total injected carbon dioxide-steam slug sizes are $0.30 \mathrm{PV}$ and alternate periods are 39 times; Finally, subsequent steam drive experiment is finished until the water cut reached more than $98 \%$.

Experimental results and analysis. During the 5 groups double tubes experiment, Enhanced oil recovery rate of steam flooding and carbon dioxide-steam flooding are recorded real-timely under 
different injection PV number. The results of the flooding experiment in different flooding ways are shown in Tab. 4.

Tab 4 Experimental data of double tube carbon dioxide-steam flooding

\begin{tabular}{|l|l|l|l|l|}
\hline \multirow{2}{*}{ Group } & \multirow{2}{*}{ Permeability difference } & \multicolumn{2}{|c|}{ Recovery (\%) } & Composite flooding \\
\cline { 3 - 5 } & & steam flooding & 4.09 & 74.10 \\
\hline 1 & 1.00 & 70.01 & 13.29 & 74.77 \\
\hline 2 & 1.85 & 61.48 & 15.51 & 71.73 \\
\hline 3 & 2.80 & 56.22 & 20.95 & 61.60 \\
\hline 4 & 3.65 & 40.65 & 23.82 & 59.70 \\
\hline 5 & 4.29 & 35.88 & & \\
\hline
\end{tabular}

According to Tab. 4, the experimental curve between carbon dioxide-steam flooding recovery and the injected PV number are drawn in Fig.4; the relationship curve between the recovery and different permeability difference are drawn in Fig. 5.

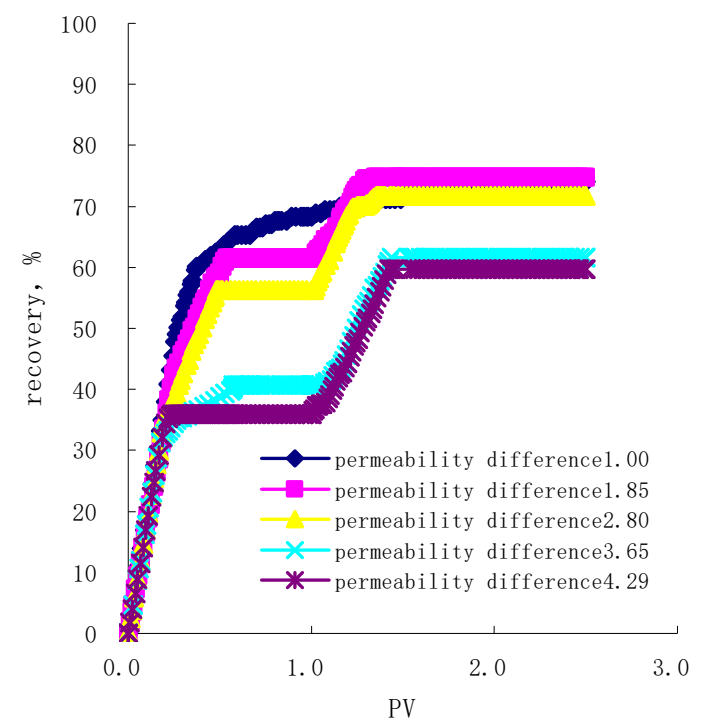

Fig. 4 Experimental curves of carbon dioxide-steam flooding

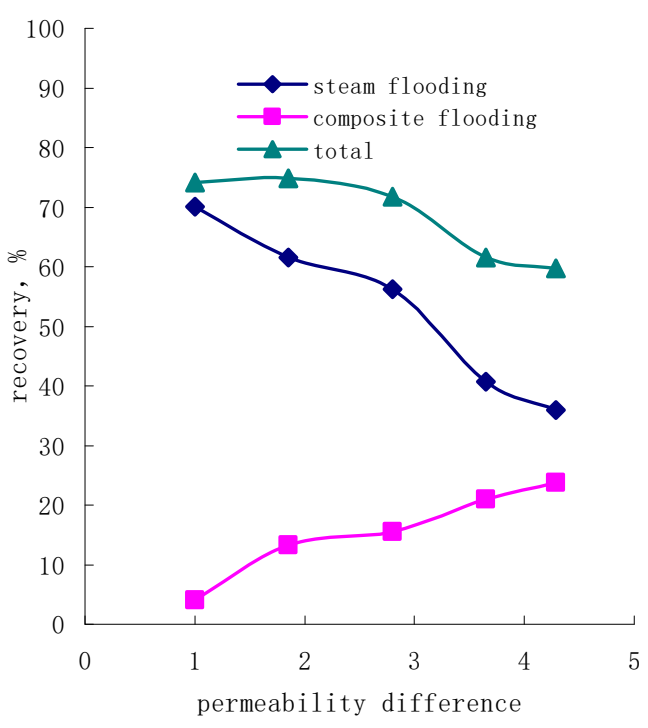

Fig. 5 Recovery curve of different permeability.

It can be seen from Fig. 5, the permeability difference of the two pipe model is in the range of $1.00 \sim 4.29$, the recovery of steam flooding is reduced by $34.22 \%$, the recovery rate of carbon dioxide-steam composite flooding is increased by $19.73 \%$, and the total oil recovery is reduced by $14.4 \%$. Although the total oil recovery is reduced when the permeability difference is in the range of $1.00 \sim 4.29$, the decreasing degree is smaller than that of steam flooding, which solves the problem of low recovery of steam flooding. Therefore, the permeability difference is in the range of $1.00 \sim 4.29$, after steam flooding, the use of carbon dioxide- steam composite flooding can increase the reservoir recovery.

The reason is that the higher the permeability difference is, the stronger the heterogeneity is. When the steam is injected, a large amount of steam enters into the high permeability model to flood oil, while the oil produced degree in the low permeability model is lower, out of the oil quantity is little. The steam flooding mainly removes the oil from the high-permeability model. The more oil is removed, the less oil is left in the model. after injection of high-temperature foaming agent, carbon dioxide-steam are injected alternately at the ratio of 1: 1, foaming agent and carbon dioxide bubbles into the high permeability layer, block the high permeability layer effectively. At this time, the injection pressure will continue to increase, the later injection of carbon dioxide-steam 
will enter into the low permeability model to flood oil. The more oil remaining after the steam flooding, the more oil is produced by carbon dioxide-steam composite flooding. Seeing from various stages of oil production, after steam flooding, the use of carbon dioxide-steam composite flooding can effectively increase the oil recovery, which is an effective method for the heavy oil production in the late steam flooding.

\section{Conclusions}

(1) After the steam flooding, the carbon dioxide-steam are altenately injected by the ratio of $1: 1$, $1: 2,1: 3$ and $1: 4$, the recovery increased by $4.09 \%, 4.47 \%, 1.93 \%$ and $2.56 \%$ respectively.Combined with the recovery of steam flooding, the carbon dioxide-steam is injected alternately in the ratio of 1 : 1 after the steam flooding, which could displace more crude oil. Therefore, the optimal ratio of carbon dioxide-steam is the ratio of 1: 1 .

(2) Double model permeability difference is in the range of $1.00 \sim 4.29$, steam flooding recovery decrease by $34.22 \%$, carbon dioxide-steam flooding recovery increase by $19.73 \%$ and the total oil recovery decrease by $14.4 \%$. Therefore, after the steam flooding, the permeability difference in the range of 1.00 4.29, using carbon dioxide-steam flooding method can increase the reservoir recovery.

\section{References}

[1] Xiao Ma. Heavy Oil Reservoirs in Steam Extraction Project Simulation Study of Foam Profile Control [D]. Shandong: China University of Petroleum, 2009: 1-86.

[2] Yao FAN, Yi-fei LIU, Ting RU, et al. Feasibility Study on High Temperature Steam Assisted Steam Flooding for Heavy Oil [J]. Petroleum Geology of Xinjiang, 2010, 31 (5): 531-532.

[3] Xian ZHANG, Yong-jian LIU, Hong-chang CHE, et al. Study on Enhancing Oil Recovery by Steam+Flue Gas+Chemical Flooding [J]. Science and Technology Engineering, 2010,10 (10): 2446-2448.

[4] Xian-xi SU. Experimental Study on Steam Flooding Assisted by Carbon Dioxide Surfactant [D]. Daqing: Northeast Petroleum University, 2014: 1-50.

[5] Tie-long Chen. Introduction to Tertiary Oil Recovery [M]. Beijing: Petroleum Industry Press, 2000: 45-50. 